\title{
Monitoring of irinotecan in human plasma: sensitive fluorescent nanogels by molecular imprinting.
}

\author{
Martina Tommasini ${ }^{1}$, Elena Pellizzoni ${ }^{1,2}$, Valentina Iacuzzi $^{2,3}$, Elena Marangon ${ }^{4}$, \\ Paola Posocco $^{5}$, Cristina Forzato ${ }^{1}$, Paolo Bertoncin ${ }^{3}$, Giuseppe Toffoli ${ }^{*}$, Marina \\ Resmini $^{6^{*}}$, Federico Berti ${ }^{1 *}$ \\ 1: Department of Chemical and Pharmaceutical Sciences, University of Trieste. Via Giorgieri 1, 34127, Trieste, Italy. \\ 2: PhD School in Nanotechnology, University of Trieste. Via Giorgieri 1, 34127, Trieste, Italy. \\ 3: Department of Life Sciences, University of Trieste. Via Giorgieri 5, 34127, Trieste, Italy. \\ 4: CRO - National Cancer Institute. Via Gallini 2, 33081, Aviano (PN), Italy. \\ 5: Department of Engineering and Architecture, University of Trieste. Via Valerio 6/1, 34127 Trieste, Italy. \\ 6: School of Biological and Chemical Sciences, Queen Mary University of London. Mile End Road, London E14NS, \\ UK. \\ *corresponding authors: fberti@units.it, m.resmini@qmul.ac.uk, gtoffoli@cro.it
}

\begin{abstract}
A series of fluorescent molecularly imprinted nanogels to detect irinotecan (CPT11) were prepared and characterized. A set of amino acids and napthalimide polymerisable derivatives allowed to obtain polymers as soluble fluorescent nanoparticles by high dilution imprinted synthesis. The direct detection of irinotecan in human plasma was obtained by fluorescence quenching of the naphtalimide-based imprinted materials. The plasma sample treated with acetonitrile allowed the detection of irinotecan in the $10 \mathrm{nM}-30 \mu \mathrm{M}$ range. The LOD was $9.4 \mathrm{nM}$, with within-run variability $10 \%$ and day to day variability $13 \%$.
\end{abstract}

\section{Introduction}

Irinotecan 1a (Camptosar®, CPT11 or 7-ethyl-10-[4-(1-piperidino)-1-piperidino]-carbonyloxycaptothecin) (Scheme 1) is an inhibitor of Topoisomerase I and is used for the treatment of metastatic colorectal cancer. It was developed by Yakult Honsha Co, Ltd, in 1983. ${ }^{1}$ It is formulated as a water soluble prodrug, administered intravenously, converted in vivo by a carboxylesterase to its active metabolite SN-38 1b (7-ethyl-10-hydroxy-camptothecin) ${ }^{2}$. 


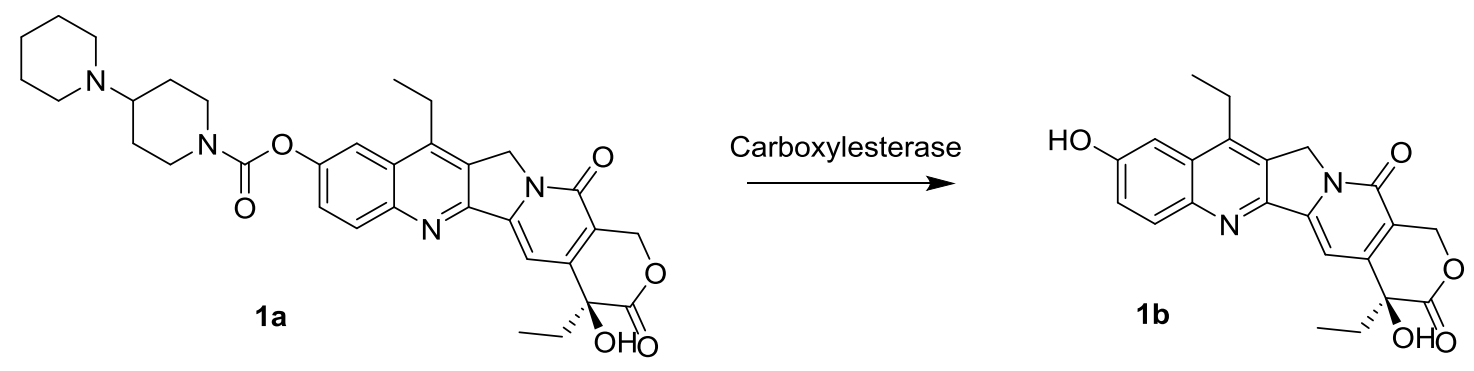

Scheme 1: Chemical Structure of Irinotecan (1a) and its active metabolite SN-38 (1b).

Irinotecan and its main metabolite, SN-38, show significant pharmacokinetic variability and many secondary effects ${ }^{3}$ and therefore their quantification in plasma is a key priority for personalised therapy. The therapeutic range of irinotecan is usually considered between $17 \mathrm{nM}$ and $17 \mu \mathrm{M}$. Therapeutic Drug Monitoring (TDM) represents an important tool to establish the best dose regimen, reduce side effects and personalize the chemotherapeutic treatment. ${ }^{4}$ Several methods have been developed to quantify irinotecan and SN-38 in human plasma by HPLC-UV, LC-MS and direct MALDI-MS quantification, ${ }^{5,6,7,8}$ however these techniques require specialised personnel, are time consuming and expensive. A point of care device may overcome these drawbacks and allow the patients to monitor directly and personalize the therapy.

To this aim, an appropriate sensor is needed to quantify the plasmatic levels of the drug, in patients samples; a sensor contains an active element able to recognize specifically and selectively a target molecule. Biomolecules, as antibodies or enzymes can be used as bio-receptors, but they show low physical and chemical stability; recently many different approaches have been developed in order to replace these natural receptors with smaller and more stable synthetic fragments. The molecularly imprinting technology is an innovative method to obtain biomimetic receptors comparable to the natural antibodies. ${ }^{9}$

Molecularly imprinted polymers (MIPs) are currently exploited in many applications, such as stationary phases for chromatography and SPE, for the sensing of small molecule analytes, ${ }^{10}$ for surface covering of gold and silver nanoparticles to use in Raman SERS, ${ }^{11}$ and drug delivery. ${ }^{12}$ Recently, the imprinting technology has been applied to soluble micro- and nano-structured materials, leading to interesting applications in catalysis ${ }^{13}$ and sensing. ${ }^{14}$

As to irinotecan, a solid phase extraction method based on molecularly imprinted polymers coupled with HPLC, was developed to detect camptothecin. The method showed a good linearity in the range of $1-200 \mu \mathrm{g} \cdot \mathrm{mL}^{-1}\left(2.9-574.2 \mu \mathrm{molL}^{-1}\right)$ and a limit of detection for captothecin of $0.13 \mu \mathrm{gmL}^{-1}$ $\left(0.4 \mu \mathrm{molL}^{-1}\right) .{ }^{15}$ The synthesis of an imprinted polymer for selective solid phase extraction of irinotecan from human serum samples was also recently reported. ${ }^{10}$ 
The aim of the present work is to design, synthesize and characterize a set of fluorescent imprinted nanogels to be used as sensors for the fluorimetric detection of 1a by exploiting the fluorescence change of a fluorescent reporter directly embedded inside the polymeric material. Four different functional monomers were selected for the synthesis of molecularly imprinted polymers using irinotecan as the template molecule. Three of these monomers (4-vynilpyridine and the fluorescent aminoacidic derivatives $\mathrm{N}$-acryloyl L-tyrosine methyl ester and $\mathrm{N}$-acryloylL-tryptophan methyl ester) have been used by us in our previous work focused on the development of a MIP sensor for the detection of the anticancer agent sunitinib in human plasma. ${ }^{16}$ The fourth functional monomer, a naphtalimide derivative, is a fluorescent molecule and its synthesis is described in this work. Through NMR titrations, the interactions of each monomer with the irinotecan were investigated. The molecularly imprinted polymers obtained were characterized through dynamic light scattering (DLS) and transmission electron microscopy (TEM); their rebinding capability was studied using an HPLC method and fluorescence measurements. The most proficient MIPs were also tested in human plasma samples.

\section{Materials and methods}

\section{Materials}

Irinotecan hydrochloride was purchased by Bepharm ltd. The other reagents and solvents were from Sigma-Aldrich. Human plasma (pool) was achieved by CRO - National Cancer Institute of Aviano.

\section{Instrumentation}

NMR spectra $(500 \mathrm{MHz})$ were recorded by a Varian 500 spectrometer. HPLC analysis were run on an Agilent 1200 liquid chromatograph equipped with a Phenomenex, Luna C18 $5 \mu$ column with a column guard and a $20 \mu \mathrm{L}$ loop. UV-visible spectra were recorded on a UV-1800 (Shimadzu) spectrometer. Fluorescence titrations were performed on a CARY Eclipse (Varian) spectrometer with a cuvette of $0.5 \mathrm{~cm}$ optical path. Polymeric particles were analysed by Dynamic Laser Light Scattering on a Zetasizer nano-S (Malvern) instrument. Microwave assisted reactions weres performed on a CEM Discover Instrument. TEM images were recorded with a Camera Olympus QUEMESA and software RADIUS (EMSIS) on a TEM Philips EM208 electron microscopy operating at $100 \mathrm{kV}$. ESI-MS were performed with an Esquire 400 (Bruker-Daltonics) spectrometer. Infrared spectra (IR) were recorded with an Avatar 320-IR FTIR (ThermoNicolet). Melting points were measured with a Sanyo Gallenkamp apparatus and were uncorrected. 


\section{Functional monomers synthesis}

The detailed procedures to obtain methyl 2-acrylamido-3-(4-hydroxyphenyl)propanoate ( $N$-acryloyl L-tyrosine methyl ester, $3 \mathbf{b}$ and $(S)$-methyl 2-acrylamido-3-(1H-indol-3-yl)propanoate ( $N$-acryloyl L-tryptophan methyl ester, $\mathbf{4 b}$ have been described in our previuos paper. ${ }^{16}$

2-allyl-6-chloro-1H-benzo[de] isoquinoline-1,3(2H)-dione 5b: $200 \mathrm{mg}(0.860 \mathrm{mmol}$, $1 \mathrm{eq})$ of 6chlorobenzo[de]isochromene-1,3-dione 5a were dissolved in $7 \mathrm{~mL}$ of ethanol and the resulting mixture was heated up under continuous stirring; at $55{ }^{\circ} \mathrm{C}, 64 \mu \mathrm{L}$ of allyl amine $(49 \mathrm{mg}, 0.853$ mmol, 1 eq) were added. The mixture was refluxed for four hours and the reaction was monitored by TLC using a 1:1 dichloromethane : ethyl acetate mixture as mobile phase. After cooling at room temperature, the solid was filtered, washed with ethanol and dried under vacuum. $142 \mathrm{mg}$ (yield $61 \%)$ of light brown powder were obtained. ${ }^{1} \mathbf{H}-\mathbf{N M R}\left(\delta, \mathrm{ppm}, 500 \mathrm{MHz}, \mathrm{CDCl}_{3}\right): 4.80\left(\mathrm{~d}, 2 \mathrm{H},{ }^{3} \mathrm{~J}=6\right.$ $\mathrm{Hz}), 5.22\left(\mathrm{dd}, 1 \mathrm{H},{ }^{3} \mathrm{~J}_{\mathrm{cis}}=10 \mathrm{~Hz},{ }^{4} \mathrm{~J}=1 \mathrm{~Hz}\right), 5.32\left(\mathrm{dd}, 1 \mathrm{H},{ }^{3} \mathrm{~J}_{\text {trans }}=17 \mathrm{~Hz}^{4} \mathrm{~J}=1 \mathrm{~Hz},\right), 5.99(\mathrm{~m}, 1 \mathrm{H}), 7.83$ $\left(\mathrm{d}, 1 \mathrm{H},{ }^{3} \mathrm{~J}_{\text {ortho }}=8 \mathrm{~Hz}\right), 7.86\left(\mathrm{t}, 1 \mathrm{H},{ }^{3} \mathrm{~J}_{\text {ortho }}=7.8 \mathrm{~Hz}\right), 8.51\left(\mathrm{~d}, 1 \mathrm{H},{ }^{3} \mathrm{~J}_{\text {ortho }}=8 \mathrm{~Hz}\right), 8.61\left(\mathrm{dd}, 1 \mathrm{H},{ }^{3} \mathrm{~J}_{\text {ortho }}=8.5\right.$ $\left.\mathrm{Hz},{ }^{4} \mathbf{J}_{\text {meta }}=1 \mathrm{~Hz}\right), 8.67\left(\mathrm{dd}, 1 \mathrm{H},{ }^{3} \mathrm{~J}_{\text {ortho }}=7 \mathrm{~Hz},{ }^{4} \mathbf{J}_{\text {meta }}=1 \mathrm{~Hz}\right) .{ }^{13} \mathbf{C}-\mathbf{N M R}\left(\delta\right.$, ppm, $\left.500 \mathrm{MHz}, \mathrm{CDCl}_{3}\right)$ : 42.66 (1C), 117.95 (1C), 121.66, 123.17 (2C), 127.55 (1C), 128.02, 129.29 (2C), 129.52 (1C), 130.90 (1C), 131.40 (1C), 132.10 (1C), 132.29 (1C), 139.32 (1C), 163.35, 163.61 (2C). IR $\left(\mathrm{cm}^{-1}\right)$ : 1781 and $1738(\mathrm{C}=\mathrm{O}), 2850$ and 2920 (C-H allyl). MS ESI (m/z): 272.3 and $274.3[\mathrm{M}+\mathrm{H}]^{+}, 294.3$ and $296.3[\mathrm{M}+\mathrm{Na}]^{+}$

2-allyl-6-((3-aminoethyl)amino)-1H-benzo[de]isoquinoline-1,3(2H)-dione 5c: The reaction of 100 $\mathrm{mg}$ of $\mathbf{5 b}(0.368 \mathrm{mmol}, 1 \mathrm{eq})$ with $1.5 \mathrm{~mL}$ of ethylene diamine $(1.35 \mathrm{~g}, \mathrm{~d}=0.90 \mathrm{~g} / \mathrm{mL}, 22.5 \mathrm{mmol})$ was assisted by microwaves. The mixture was heated up to $85^{\circ} \mathrm{C}$ for 2 hours and the reaction was monitored by TLC using a 1:1 dichloromethane : ethyl acetate mixture as mobile phase. Then $7 \mathrm{~mL}$ of water were added and the mixture was cooled overnight at $4{ }^{\circ} \mathrm{C}$. The resulting solid was filtered under vacuum, washed with cold water and dried at $60{ }^{\circ} \mathrm{C}$ for two days. $100 \mathrm{mg}$ of pure $\mathbf{5 c}$ were obtained as an orange solid (yield 92\%). ${ }^{\mathbf{H}} \mathbf{H}-\mathbf{N M R}\left(\delta\right.$, ppm, $\left.500 \mathrm{MHz}, \mathrm{CDCl}_{3}\right): 3.18$ (s, 2H), 3.41 $\left(\mathrm{d},{ }^{3} \mathrm{~J}=4 \mathrm{~Hz}, 2 \mathrm{H}\right), 4.79\left(\mathrm{~d},{ }^{3} \mathrm{~J}=4 \mathrm{~Hz}, 2 \mathrm{H}\right), 5.18\left(\mathrm{~d},{ }^{3} \mathrm{~J}_{\mathrm{cis}}=10 \mathrm{~Hz}, 1 \mathrm{H}\right), 5.29\left(\mathrm{~d},{ }^{3} \mathrm{~J}_{\text {trans }}=17 \mathrm{~Hz}, 1 \mathrm{H}\right), 6.00$ $(\mathrm{m}, 1 \mathrm{H}), 6.19(1 \mathrm{H}), 6.705\left(\mathrm{~d},{ }^{3} \mathrm{~J}_{\text {ortho }}=8.4 \mathrm{~Hz}, 1 \mathrm{H}\right), 7.62\left(\mathrm{t},{ }^{3} \mathrm{~J}_{\text {ortho }}=7.6 \mathrm{~Hz}, 1 \mathrm{H}\right), 8.18\left(\mathrm{~d},{ }^{3} \mathrm{~J}_{\text {ortho }}=8.3\right.$ $\mathrm{Hz}, 1 \mathrm{H}), 8.46\left(\mathrm{~d},{ }^{3} \mathrm{~J}_{\text {ortho }}=8.2 \mathrm{~Hz}, 1 \mathrm{H}\right), 8.59\left(\mathrm{~d}, 1 \mathrm{H},{ }^{3} \mathrm{~J}_{\text {ortho }}=7.1 \mathrm{~Hz}\right) .{ }^{13} \mathbf{C}-\mathbf{N M R}(\delta$, ppm, $500 \mathrm{MHz}$, $\mathrm{CDCl}_{3}$ ): 40.30 (1C), 42.31 (1C), 44.99 (1C), 104.62 (1C), 110.29 (1C), 117.12 (1C), 120.65 (1C), 123.16 (1C), 124.85 (1C), 126.49 (1C), 130.06 (1C), 131.42 (1C), 132.87 (1C), 134.81 (1C), 149.93 
(1C), 164.03, 164.61 (2C). m.p.: $169^{\circ} \mathrm{C}$. IR $\left(\mathrm{cm}^{-1}\right): 3360$ (N-H), 2854 and 2924 (C-H allyl), 1635 $(\mathrm{C}=\mathrm{O}), 1558(\mathrm{C}=\mathrm{C}) . \operatorname{MS} \operatorname{ESI}(\mathrm{m} / \mathrm{z}): 296.4[\mathrm{M}+\mathrm{H}]^{+}$

\section{${ }^{1} H$-NMR titrations}

The interactions between the functional monomers and the template molecule were investigated by titrating 1a with each functional monomer. To a $5.3 \mathrm{mM}$ solution of $\mathbf{1 a}(3.0 \mathrm{mg}, 4.4 \mu \mathrm{mol})$ in 840 $\mu \mathrm{L}$ of $\left[\mathrm{D}_{6}\right] \mathrm{DMSO}$, increasing amounts of functional monomers $\mathbf{2}, \mathbf{3 b}$ or $\mathbf{4 b}$ (from $2.6 \mathrm{mM}$ to 74.2 $\mathrm{mM})$ were added. The titration with monomer $\mathbf{5 c}$ was performed using $4 \mathrm{mM}$ irinotecan- $\mathrm{HCl}(2.3$ $\mathrm{mg}, 3.40 \mu \mathrm{mol})$ in $850 \mu \mathrm{L}$ of $\left[\mathrm{D}_{6}\right] \mathrm{DMSO}$ and addition of increasing concentrations of $\mathbf{5 c}$ from 2 $\mathrm{mM}$ to $40 \mathrm{mM}$. ${ }^{1} \mathrm{H}$ NMR spectra were recorded after each addition.

\section{MIP synthesis}

The molecularly imprinted polymers were prepared following the procedure described in our recent paper. ${ }^{16}$ A pre-polymerization complex was prepared stirring a solution of the template molecule and the functional monomer in DMSO under anhydrous conditions, then the cross-linker and radical initiator AIBN were added to the mixture. After oxygen removal from the solution, radical polymerization was initiated by heating up to $70{ }^{\circ} \mathrm{C}$ for 4 days. The template was finally removed by dialysis against water and acidic methanol, and polymers were freeze-dried. For each MIP a corresponding non-imprinted polymer (NIP) was prepared, using the same MIP composition, except for the template molecule.

\section{Dynamic laser light scattering}

$0.25 \mathrm{mg} \mathrm{mL}^{-1} \mathrm{DMSO}$ solutions of each MIP and NIP were filtered on $0.45 \mu \mathrm{m}$ filters and the size distributions by number, intensity and volume were recorded in triplicate on a Malvern Zetasizer Nano instrument using a $1 \mathrm{~mL}$ quartz cuvette with light path of $1 \mathrm{~cm}$.

\section{Transmission electron microscopy}

MIP 1.5 was suspended in distilled water $\left(0.2 \mathrm{mgmL}^{-1}\right)$ and sonicated for 30 minutes. This solution was then diluted 40 times with distilled water and sonicated for 1 hour. A drop of this solution was then placed on an amorphous carbon coated grid and left it to dryness at room temperature for one night; TEM images of MIP 1.5 were finally recorded.

\section{Incorporation of functional monomer $\mathbf{5 c}$}


A calibration curve of 5c in DMSO was first built recording the UV spectra of batch monomer solutions $(10-70 \mu \mathrm{M})$. The UV spectra of two solutions of MIP 1.5 and NIP 0.5 in DMSO (300 and $600 \mu \mathrm{gmL}^{-1}$ ) were recorded and the number of moles of monomer $\mathbf{5 c}$ per $\mathrm{mg}$ of polymer was calculated.

\section{Irinotecan rebinding tests}

The rebinding kinetics of 1a to MIPs were investigated by suspending $1.5 \mathrm{mg}$ of polymer in $1.5 \mathrm{~mL}$ of a $50 \mu \mathrm{M}$ 1a water solution. The mixtures were incubated at $25^{\circ} \mathrm{C}$ under continuous stirring and $200 \mu \mathrm{L}$ aliquots were taken after different times (from $10 \mathrm{~min}$ to $12 \mathrm{~h}$ ). The polymer was removed by centrifugation (10000 rpm for $6 \mathrm{~min}$ ) and the solution supernatant was analysed by HPLC. The amount of irinotecan captured by the polymer was calculated from a calibration curve. The HPLC analyses were run at $25{ }^{\circ} \mathrm{C}$ using a $75: 25$ water : acetonitrile mobile phase with $0.05 \%$ of TFA, at a flux of $1 \mathrm{mLmin}^{-1}$ and UV detection at $363 \mathrm{~nm}$.

\section{Fluorescence titrations}

$60 \mu \mathrm{gmL}^{-1}$ solutions of the fluorescent polymers MIP 1.3 and MIP 1.4 in 4:1 DMSO : water mixtures were titrated with increasing amounts of 1a, from $1 \mu \mathrm{M}$ to $250 \mu \mathrm{M}$. The emission and excitation wavelengths were $318 \mathrm{~nm}$ and $274 \mathrm{~nm}$ for MIP 1.3 (20 and $10 \mathrm{~nm}$ excitation and emission slits), $350 \mathrm{~nm}$ and $280 \mathrm{~nm}$ for MIP 1.4 (10 $\mathrm{nm}$ both excitation and emission slits).

$60 \mu \mathrm{gmL}^{-1}$ solutions of MIP 1.5 in 3:1 methanol : water and 3:1 acetonitrile : water mixtures were titrated with increasing amounts of $1 \mathbf{a}$, from $20 \mathrm{nM}$ to $25 \mu \mathrm{M}$, using excitation and emission wavelengths of 448 and $525 \mathrm{~nm}$ (10 and $5 \mathrm{~nm}$ excitation and emission slits).

\section{Plasma treatment}

Plasma samples were treated with methanol to precipitate proteins. By adding three volumes of methanol or acetonitrile to one volume of plasma, precipitation occurred; after at least three centrifugation runs $\left(10 \mathrm{~min}\right.$ at $13000 \mathrm{rpm}$, at $\left.4{ }^{\circ} \mathrm{C}\right)$ the supernatant solutions were ready to be used.

\section{MIP 1.3 assays in plasma}

$1 \mu \mathrm{M} 1 \mathrm{a}$ in 3:1 methanol : plasma mixture was titrated with increasing amounts of MIP 1.3 using 10, 50 and $250 \mu \mathrm{gmL}^{-1} \mathrm{MIP}$ solutions in 3:1 DMSO : water mixture. Fluorescence emission of irinotecan was measured before and after the addition of polymer, using excitation and emission wavelengths of respectively $360 \mathrm{~nm}$ and $430 \mathrm{~nm}$. The same experiment was replicated with $1 \mu \mathrm{M}$ 1a in 3:1 DMSO : plasma mixture, and in 3:1 methanol : plasma mixtures for $0.25 \mu \mathrm{M}, 0.5 \mu \mathrm{M}, 1$ 
$\mu \mathrm{M}$ and $4.25 \mu \mathrm{M}$ irinotecan solutions, adjusting the excitation and emission slits during the experiment.

Calibration curve of MIP 1.3 in 3:1 methanol : plasma

$2 \mu \mathrm{g}$ of MIP $1.3\left(2 \mu \mathrm{L}\right.$ of $1 \mathrm{mgmL}^{-1}$ polymer solution in 3:1 DMSO:water) were added to samples containing different concentrations of irinotecan from $0.5 \mu \mathrm{M}$ to $8 \mu \mathrm{M}$ in $3: 1$ methanol : plasma mixtures. Irinotecan fluorescence emission was measured at $430 \mathrm{~nm}$ before and $30 \mathrm{~min}$ after the addition of the polymer, using an excitation wavelength of $360 \mathrm{~nm}$.

\section{Fluorescence titration of MIP 1.5 in treated plasma}

$400 \mu \mathrm{L}$ of $60 \mu \mathrm{gmL}^{-1}$ MIP 1.5 solution in a 3:1 acetonitrile : plasma mixture were titrated with increasing concentrations of irinotecan from $20 \mathrm{nM}$ to $25 \mu \mathrm{M}$, using excitation and emission wavelengths of respectively $448 \mathrm{~nm}$ and $525 \mathrm{~nm}$, and both excitation and emission slits of $5 \mathrm{~nm}$.

\section{Results and discussion}

\section{Selection of functional monomers}

The non-covalent approach for the synthesis of molecularly imprinted nanoparticles first requires the choice of functional monomers able to bind the target molecule, through weak interactions as $\pi$ $\pi$ stacking, hydrogen bonds or hydrophobic interactions. The formation of template-functional monomer complex is necessary to achieve specific binding sites in the MIPs.

To this aim, five functional monomers were selected: 4-vinylpyridine 2, a common and commercially available monomer used for MIPs synthesis, ${ }^{17,18,19} \mathrm{~N}$-acryloyl-tryptophan methyl ester $\mathbf{3 b}$ and $\mathrm{N}$-acryloyl-tyrosine methyl ester $\mathbf{4 b}$, amino acid-based monomers that can mimic the interactions occurring between the drug and a protein in its binding site (Scheme 2). ${ }^{20}$ Compounds 3b and 4b were obtained by acylating their relative precursors with acryloyl chloride. Finally the fluorescent functional monomer 5c, 2-allyl-6-((3-aminoethyl)amino)-1H-benzo[de]isoquinoline1,3(2H)-dione, was synthesized from $\mathbf{5} \mathbf{a}^{21}$ using allylamine to obtain a polymerizable double bond and ethylenediamine to obtain an amino group that could establish hydrogen bonds with irinotecan (Scheme 3). 


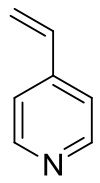<smiles>[R]C(Cc1ccc(O)cc1)C(C)=O</smiles>

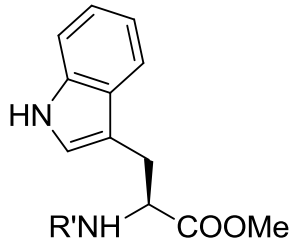

a: $\mathrm{R}^{\prime}=\mathrm{H}$

$\mathrm{b}: \mathrm{R}^{\prime}=\prod_{\mathrm{O}}$

Scheme 2: Chemical structure of functional monomers used in this work: 4-vinylpyridine 2, N-acryloyl L-tyrosine methyl ester $\mathbf{3 b}$ and N-acryloyl L-tryptophan methyl ester $\mathbf{4 b}$<smiles>C=CCN1C(=O)c2cccc3c(Cl)ccc(c23)C(=O)N1CC=C</smiles>

Scheme 3: Synthesis of 2-allyl-6-((3-aminoethyl)amino)-1H-benzo[de]isoquinoline-1,3(2H)-dione 5c

The formation of the template-functional monomer complex was studied through ${ }^{1} \mathrm{H}-\mathrm{NMR}$ titrations in DMSO- $\mathrm{d}_{6}$, by adding increasing amounts of functional monomers to irinotecan. The variations of chemical shifts of each irinotecan proton, mainly involved in the interaction with the functional monomer, were observed; consequently it was possible to identify the groups of both the target and the functional monomer mainly involved in the formation of the irinotecan-functional monomer complex.

Irinotecan interacts mainly at its protonated piperidine group. The upfield shift of this proton indicates a shield effect on this positive charged $\mathrm{NH}$ due to the interactions with functional monomers polar groups. N-acryloyl-tryptophan methyl ester interacted better than other functional monomers mainly by hydrogen bonds with the protonated piperidinium group of irinotecan (Figure 1). All the functional monomers were also able to establish $\pi-\pi$ staking interactions with their aromatic protons, leading to smaller variations of chemical shifts. 


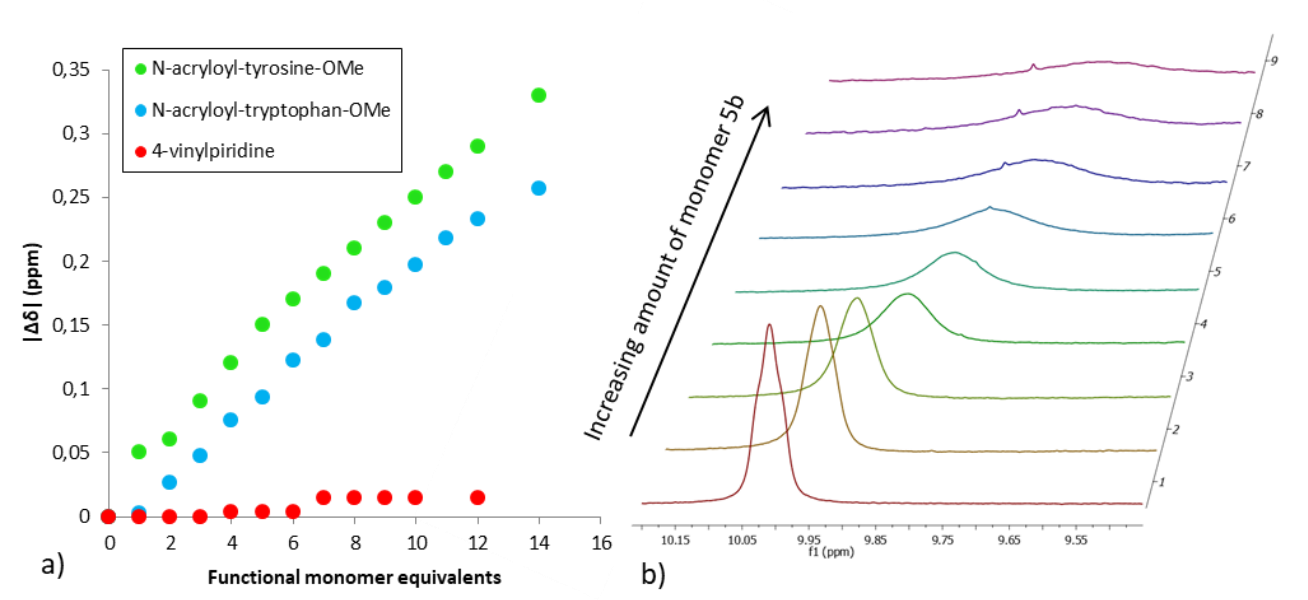

Figure 1: a) Variation of NH proton chemical shift of irinotecan upon interaction with the functional monomers; b) shifts of $\mathrm{NH}$ group of irinotecan upon adding of $\mathrm{N}$-acryloyl-tyrosine methyl ester $\mathbf{5 b}$

The interaction between $\mathbf{1 a}$ and the naphtalimidic fuctional monomer 5c occurred mainly at the piperidinium group due to the deprotonation of the irinotecan group by the functional monomer; this was confirmed by the disappearance of the characteristic peak of the irinotecan piperidinium proton after addition of 0.5 equivalents of functional monomer (Figure 2b). Such proton transfer led also to chemical shifts variation of adjacent protons. Large proton shift was, indeed, observed for equatorials H19, H20, H22, H23, H26 and axial H20 (Figure 2a), all belonging to the bispiperidinium moiety of irinotecan; the corresponding trends reached a plateau after the addition of one equivalent of monomer $\mathbf{5 c}$, confirming that a strong interaction occurred between the drug and the functional monomer. Finally $\pi-\pi$-staking interactions also occurred between the aromatic structure of napthalimide and the quinoline moiety of the anticancer agent. In general, such interactions showed higher entity of chemical shift variations than the ones observed adding functional monomers $\mathbf{3 b}$ and $\mathbf{4 b}$. 


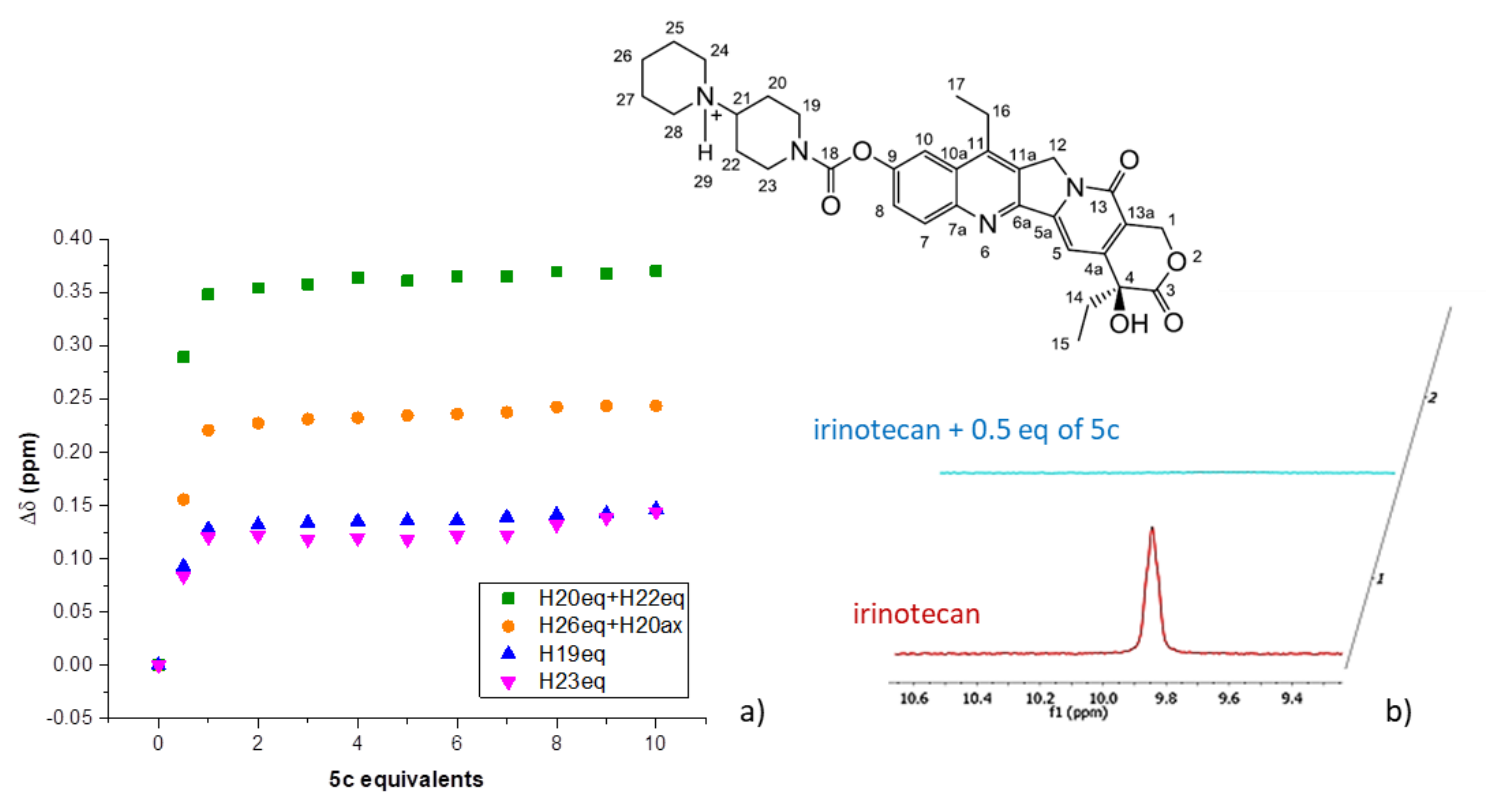

Figure 2: Variation of proton chemical shift of irinotecan protons H20eq+H22eq, H26eq+H20ax, H19eq and H23eq upon interaction with $\mathbf{5 c}$ (left); b) disappearance of -piperidinium proton of irinotecan upon interaction with 5c (right)

\section{MIPs synthesis and characterization}

Molecularly imprinted nanoparticles were synthesized by high dilution radical polymerization, following the procedure described in our previous paper. ${ }^{19}$ Nanogels composition and yield are listed in Table 1.

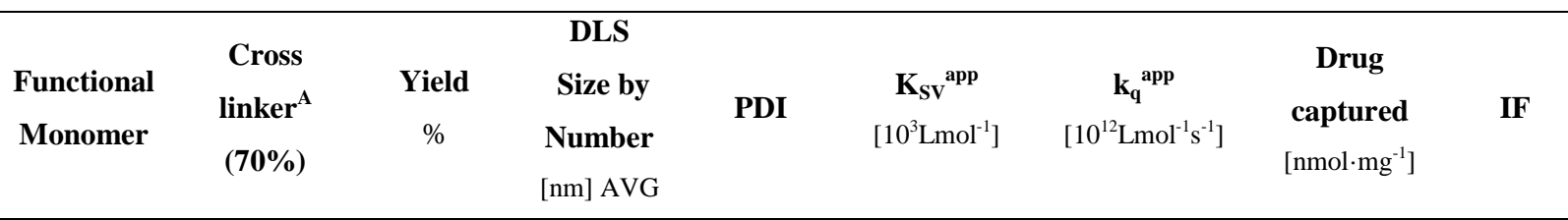

\begin{tabular}{cccccccccc}
$\underline{\text { MIPs }}$ & & & & & & & & & \\
$\mathbf{1 . 2}$ & $2(15 \%)$ & EBA & 45 & $8.1 \pm 1.3$ & 0.569 & - & - & 7 & 1 \\
$\mathbf{1 . 3}$ & $3 \mathrm{~b}(15 \%)$ & EBA & 68 & $8.5 \pm 0.9$ & 0.890 & 10.4 & 2.9 & 10 & 5 \\
$\mathbf{1 . 4}$ & $4 \mathrm{~b}(15 \%)$ & EBA & 77 & $8.1 \pm 0.6$ & 0.921 & 18.2 & 5.9 & 6 & 3 \\
$\mathbf{1 . 5}$ & $5 \mathrm{c}(30 \%)$ & EGDMA & 77 & $13.1 \pm 2.0$ & 0.387 & 606.4 & 50.7 & 19 & 2 \\
$\underline{\mathrm{NIPs}}$ & & & & & & & & & \\
$\mathbf{0 . 2}$ & $2(15 \%)$ & EBA & 94 & $11.7 \pm 2.9$ & 0.614 & - & - & 5 & - \\
$\mathbf{0 . 3}$ & $3 \mathrm{~b}(15 \%)$ & EBA & 35 & $5.8 \pm 0.7$ & 0.655 & 4.8 & 1.3 & 2 & - \\
$\mathbf{0 . 4}$ & $4 \mathrm{~b}(15 \%)$ & EBA & 79 & $6.2 \pm 0.5$ & 0.447 & 16.2 & 5.2 & 2 & - \\
$\mathbf{0 . 5}$ & $5 \mathrm{c}(30 \%)$ & EGDMA & 42 & $15.5 \pm 1.8$ & 0.227 & - & - & 12 & - \\
\hline
\end{tabular}

Table 1: MIPs and NIPs composition, yield and characterization results: polymer size was measured in DMSO solutions by DLS, apparent Stern-Volmer and quenching constants were obtained from fluorescence titrations of 60 $\mu \mathrm{g} / \mathrm{mL}$ fluorescent MIP with irinotecan (in 4:1 DMSO:water for MIPs 1.3, 1.4 and NIPs 0.3, 0.4; in 3:1 
acetonitrile:water for MIP 1.5). The amount of drug captured by the polymer, after 3 hours of incubation, was calculated by rebinding tests, using HPLC method. ${ }^{A}$ EBA: N,N'-Ethylenebis(acrylamide), EGDMA: Ethylene glycol dimethacrylate. PDI indicates the Polymer Dispersion Index. IF is the Imprinting Factor and corresponds to the ratio between the template moles captured by MIP and those by NIP.

The resulting polymers were analysed by DLS in DMSO solutions after filtering on $0.22 \mu \mathrm{m}$ filter. All samples showed particles size around $10 \mathrm{~nm}$. The particles size of MIP 1.5 was also investigated by transmission electron microscopy, using a carbon coated grid; the relative images are reported in Figure 3 and give an average particle size of $6.2 \pm 3.4 \mathrm{~nm}$. This result is consistent with the one obtained by DLS, as in TEM measures the solvation sphere is obviously not present. The particles dimensions observed at TEM are comparable to those reported in the literature. ${ }^{22}$
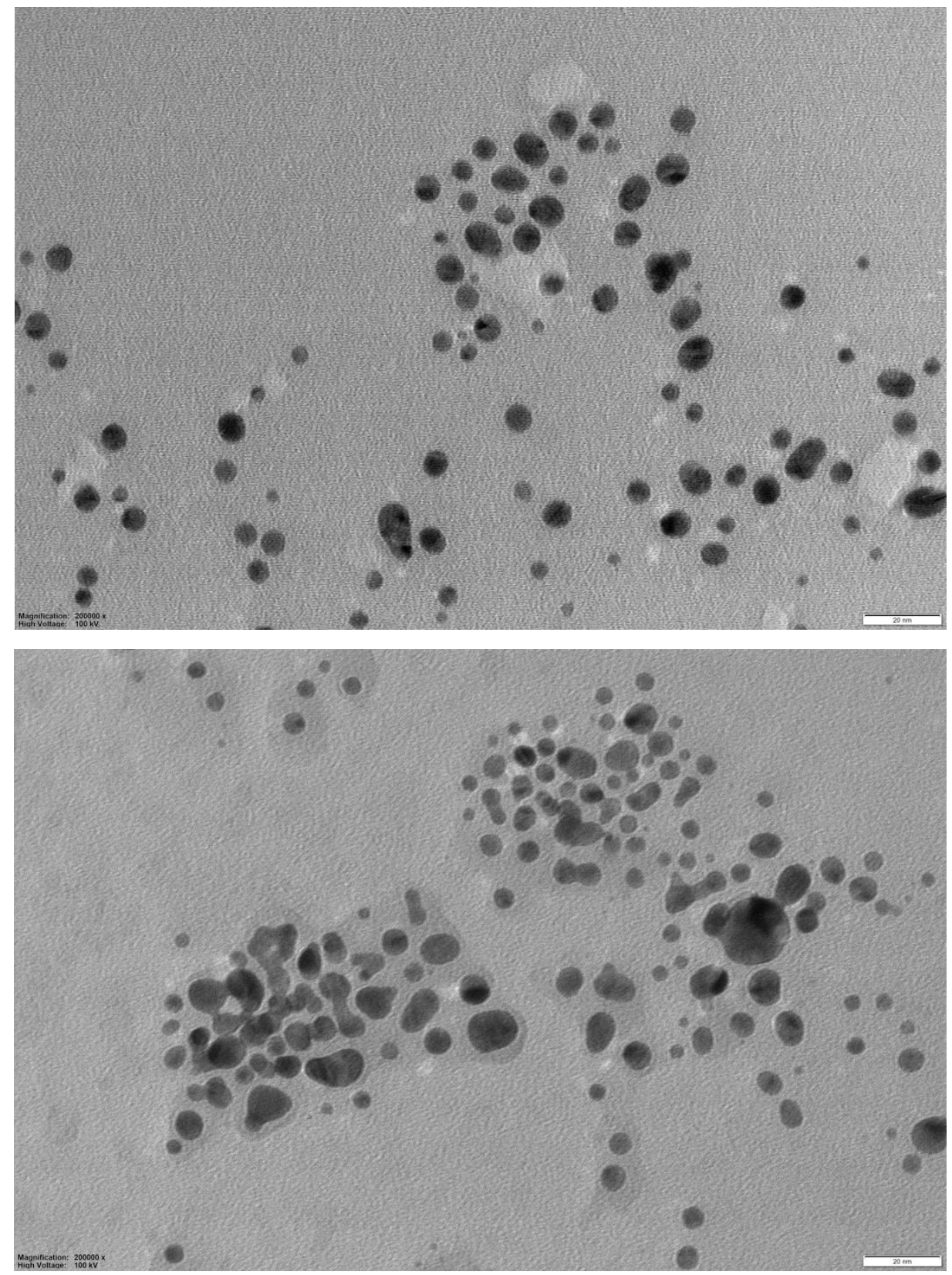

Figure 3: TEM images of MIP 1.5 
For MIP 1.5 and NIP $\mathbf{0 . 5}$ polymers, the amount of the monomer 5c incorporated, after the polymerization, was determined through UV absorption measurements. MIP 1.5 and NIP $\mathbf{0 . 5}$ incorporated similar amount of the monomer, $35.9 \mathrm{nmol}$ and $37.6 \mathrm{nmol}$ in $1 \mathrm{mgmL}^{-1}$ solution respectively. This result allows us to consider NIP $\mathbf{0 . 5}$ as a control polymer for the corresponding MIP 1.5, and compare their binding capability to establish MIP specificity.

\section{Rebinding of irinotecan}

MIPs binding capabilities were investigated by rebinding tests; $1 \mathrm{mgmL}^{-1}$ water suspension of each MIP was incubated with $50 \mu \mathrm{M}$ irinotecan and after different times, the drug left in solution was quantified by an HPLC method. By difference it was possible to calculate the amount of irinotecan captured by MIPs. Binding capability of MIPs was also compared to that of non-imprinted polymers (NIPs): all the MIPs showed more affinity to irinotecan (Table 1), rather than corresponding NIPs, confirming that imprinting was successful (Figure 3). MIP 1.5 and NIP 0.5 were also analysed after 24 hours of incubation with the drug, showing a further increased amount of irinotecan captured by MIP 1.5 (29 nmol/ mg of MIP), and an unchanged quantity of template bound by NIP 0.5, equal to $12 \mathrm{nmol}$ of irinotecan per mg of NIP. These results proved that MIP $\mathbf{1 . 5}$ captured the highest amount of irinotecan, compared to all the polymers synthesized, and showed an Imprinting Factor of 2.4 after 24 hours of incubation, confirming good specificity.

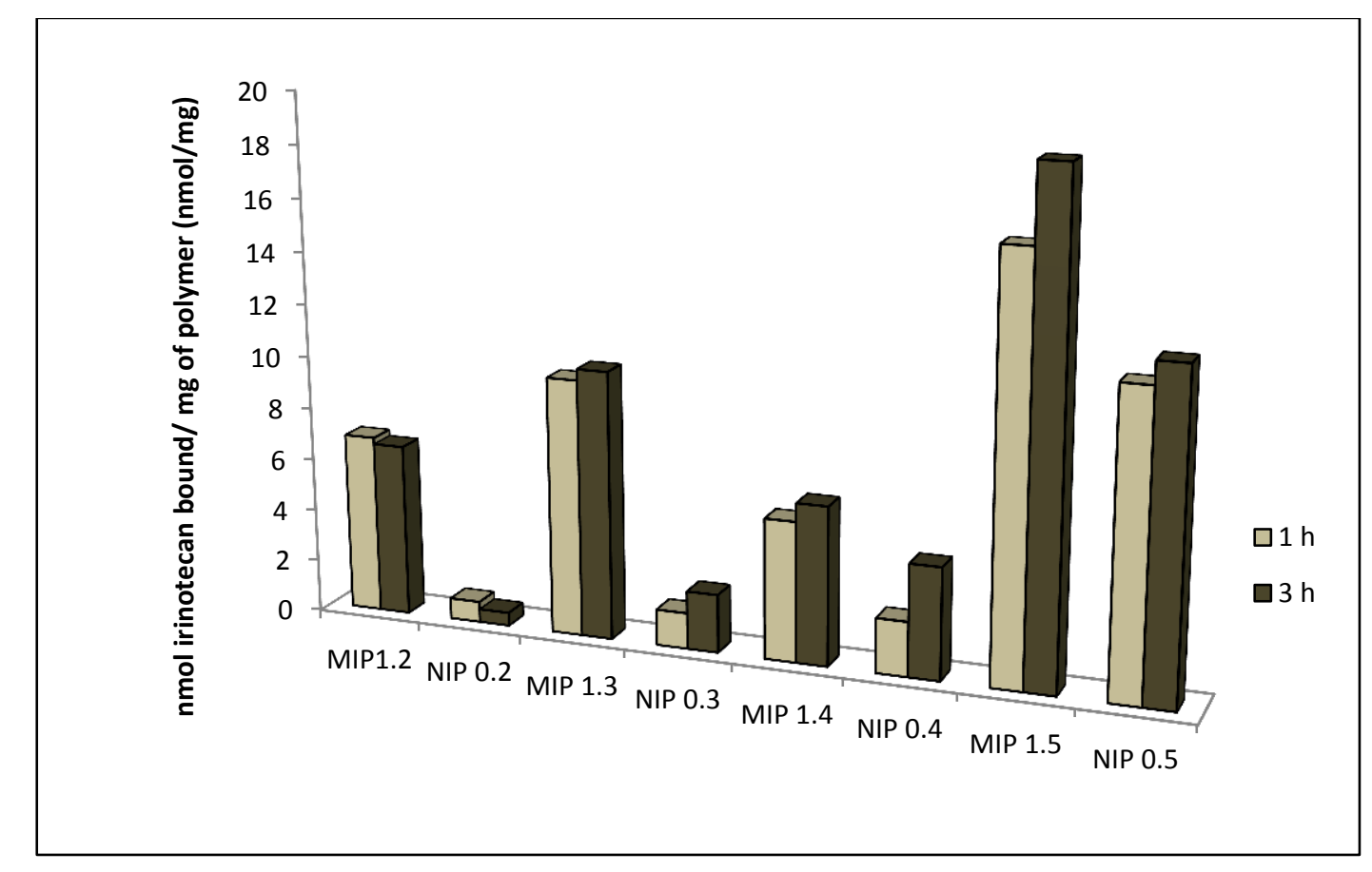




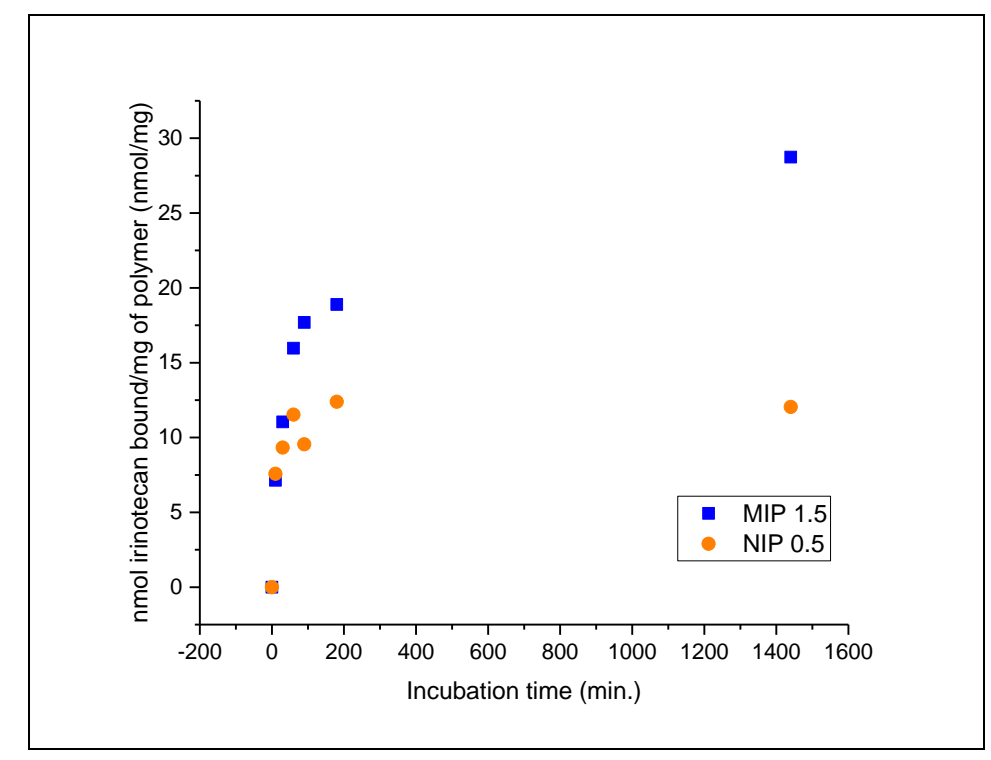

b

Figure 3: a: rebinding after 1 and 3 hours for all the polymers; b: rebinding kinetics of irinotecan by MIP 1.5 and NIP 0.5 , containing monomer $\mathbf{5 c}$, in water.

\section{Fluorimetry}

The fluorescence emission of the MIPs was quenched upon binding with the drug. Data were analysed by Stern-Volmer analysis, after correction of the quenching data by inner filter effects. ${ }^{23}$ The apparent quenching constants $\left(\mathrm{k}_{\mathrm{q}}^{\mathrm{app}}\right)$ were also calculated for each polymer using the lifetime of fluorophores $\left(\tau_{0}\right)$ which were assumed to be $3.6 \cdot 10^{-9} \mathrm{~s}$ for tyrosine, ${ }^{24} 3.1 \cdot 10^{-9} \mathrm{~s}$ for tryptophan ${ }^{25}$ and $8.3 \cdot 10^{-9} \mathrm{~s}$ for the napthalimide derivative $\mathbf{5 c} .^{26}$ The results are listed in Table $\mathbf{1}$.

All the resulting apparent quenching constants were larger than the expected values for the diffusion controlled quenching $1 \cdot 10^{10} \mathrm{Lmol}^{-1} \mathrm{~s}^{-1}$, therefore the observed quenching can be considered a static phenomenon occurring upon binding of irinotecan to the binding site.

\section{Detection of irinotecan in plasma}

\section{MIP 1.3}

Titrations of both MIP 1.3 and NIP $\mathbf{0 . 3}$ at $60 \mu \mathrm{gmL}^{-1}$ were performed in a 4:1 DMSO : water mixture with increasing amounts of irinotecan. At low irinotecan concentrations $(1 \mu \mathrm{M}-250 \mu \mathrm{M}$ range), a linear behaviour was observed (Figure 4a). MIP 1.3 proved a good fluorescence quenching in the micromolar range and an higher apparent Stern-Volmer constant $\left(10.4 \cdot 10^{3} \mathrm{Lmol}^{-1}\right)$ than the corresponding non-imprinted polymer $\left(4.8 \cdot 10^{3} \mathrm{Lmol}^{-1}\right)$, confirming its good specificity for irinotecan, as observed also by rebinding tests at HPLC. 
a)

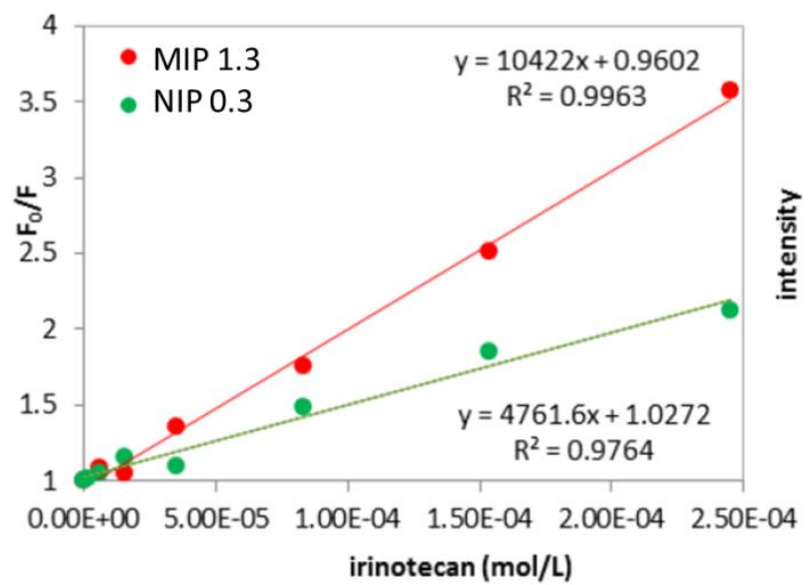

b)

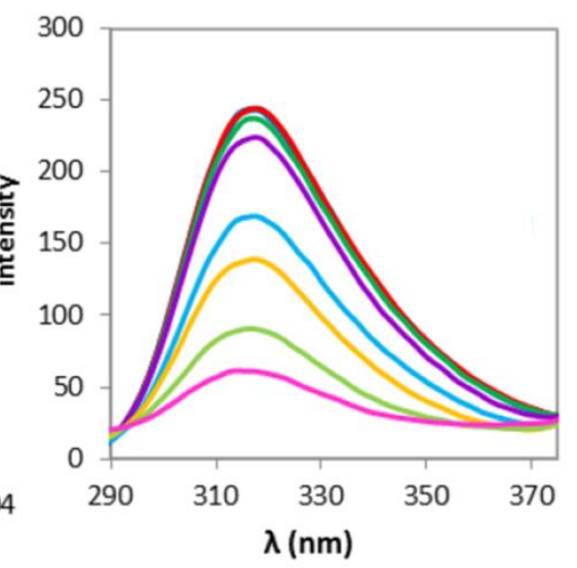

Figure4: a) Stern - Volmer plots of MIP 1.3 and the corresponding NIP 0.3 $(60 \mu \mathrm{gmL})$ in 4:1 DMSO : water mixture; b) quenching of MIP 1.3 fluorescence upon addition of irinotecan in 4:1 DMSO water mixture

In spite of the good fluorescence quenching of MIP 1.3 observed upon binding with irinotecan in 4:1 DMSO:water, this approach could not be used in treated plasma samples due to the presence of proteins and peptides themselves containing tyrosine, which interferes with MIP fluorescence emission. We have consequently tested the possibility to exploit these MIPs as quenchers of the intrinsic fluorescence emission of irinotecan, which emits fluorescence at $430 \mathrm{~nm}$ when excited at $360 \mathrm{~nm}$. MIP1.3 ability to quench $1 \mu \mathrm{M}$ irinotecan fluorescence emission was first tested by fluorescence titration in both 3:1 methanol : plasma and 3:1 DMSO : plasma mixtures, by adding increasing amounts of the polymer. DMSO was chosen to study the MIP binding capability in the same solvent used for the polymerization, while methanol is the common extraction solvent adopted to quantify irinotecan in patients samples. The addition of DMSO to plasma does not lead to precipitation of proteins, but only to their denaturation, ${ }^{27,28}$ instead the addition of methanol caused the precipitation of the proteins. Despite these different environments, MIP 1.3 showed the same behaviour during both the titrations and it was able to quench the irinotecan fluorescence reaching a plateau after $2 \mu \mathrm{g}$ of polymer added, in both media (Figure 5). 


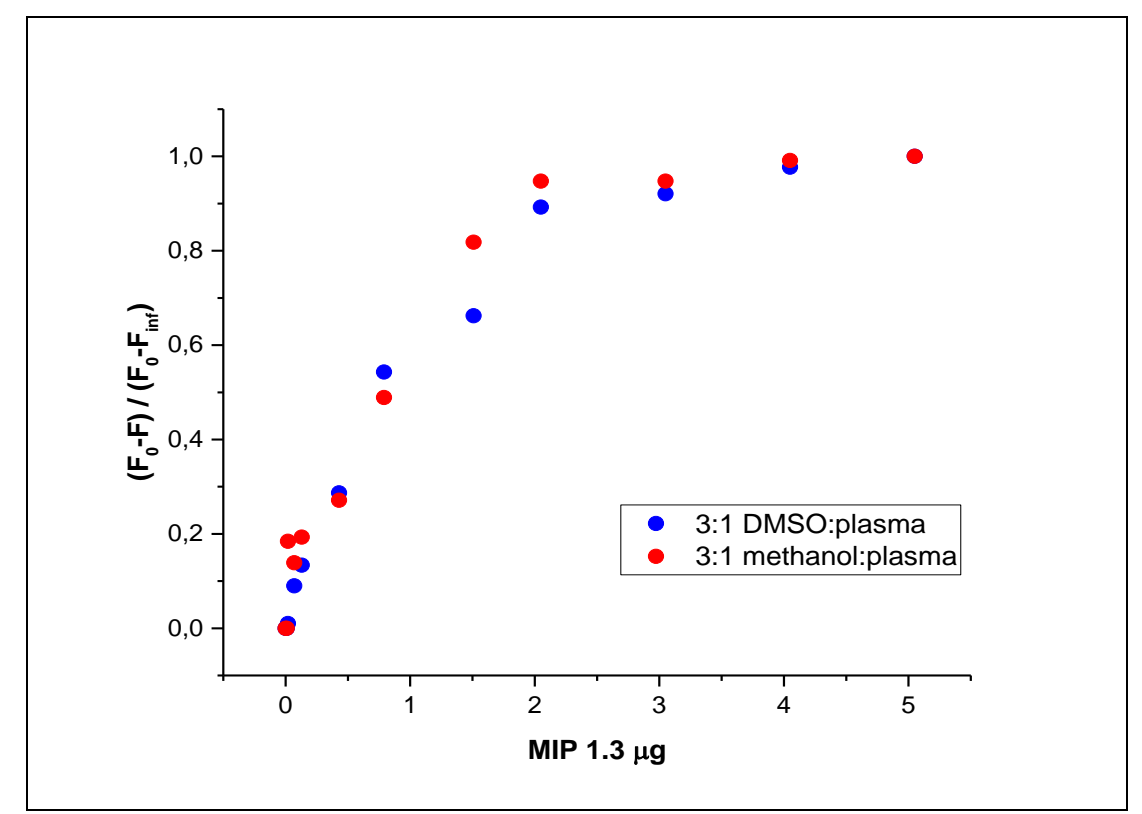

Figure 5: titration curve of $1 \mu \mathrm{M}$ 1a with MIP 1.3 in 3:1 methanol : plasma (red) and 3:1 DMSO : plasma (blue) mixture

A preliminary calibration curve was carried out treating spiked samples containing different concentrations of irinotecan in 3:1 methanol : plasma mixture with $2 \mu \mathrm{g}$ of MIP 1.3. The fluorescence emission before and after addition of the polymer was measured exciting at $360 \mathrm{~nm}$ and measuring emission at $430 \mathrm{~nm}$. The amount of $2 \mu \mathrm{g}$ of polymer added was chosen because in the previous titration curves a plateau was reached after the addition of $2 \mu \mathrm{g}$ of MIP 1.3.

Even if the amount of quenching was not very high, a linear correlation was observed from $0.5 \mu \mathrm{M}$ to $8 \mu \mathrm{M}$ drug (Figure 6). This proof of concept shows that MIP $\mathbf{1 . 3}$ is able to work in plasma samples without significant decrease of its performance, even in presence of methanol.

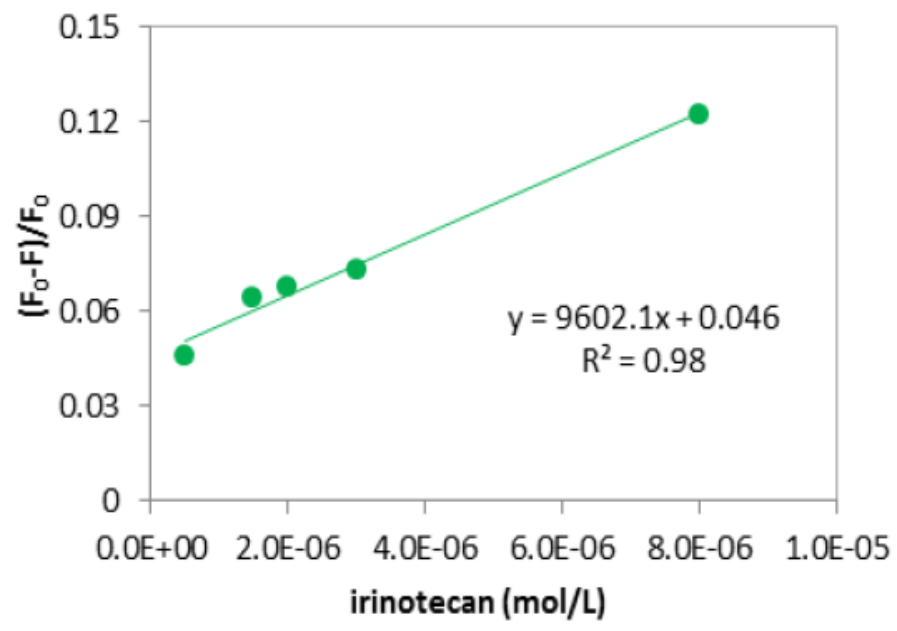

Figure 6: Preliminary calibration curve of irinotecan with MIP 1.3 in 3:1 methanol : plasma mixture 


\section{$\underline{\text { MIP } 1.5}$}

A second approach to develop sensors for irinotecan consists in exploiting MIP fluorescence, whose emission can be quenched upon interaction with the drug. To this aim, fluorescence titrations of 60 $\mu \mathrm{gmL}^{-1}$ MIP 1.5 were performed with increasing amounts of irinotecan in 3:1 methanol : water and 3:1 acetonitrile : water mixtures, to select the best solvent for MIP performance. Methanol was chosen after having demonstrated on MIP 1.3 that this solvent does not affect the performance of our MIPs in water mixture. Acetonitrile was conversely considered because several LC methods for the detection of irinotecan have been proven to yield better recovery when human plasma is treated with this solvent (the recovery is typically no higher than $64 \%$ average from low, medium and high concentration spiked samples, in the reference literature). ${ }^{6}$ In the resulting Stern-Volmer plots, linear behaviours were observed within 20 - $100 \mathrm{nM}$ range; very high apparent Stern-Volmer constants $\left(606.4 \cdot 10^{3} \mathrm{Lmol}^{-1}\right.$ in $3: 1$ acetonitrile:water and $431.2 \cdot 10^{3} \mathrm{Lmol}^{-1}$ in $3: 1$ methanol : water) were observed, leading to a great increase of MIP sensitivity at low drug concentrations, compared to MIP 1.3 (Fig. 7, insert). Moreover, the fluorescence emission of naphtalimide occurs at higher wavelengths than both irinotecan and plasma biomolecules, allowing drug quantification in biological samples without any interference. Considering the whole range of irinotecan concentration, the best performance was obtained in a 3:1 acetonitrile : water mixture (Fig. 7).

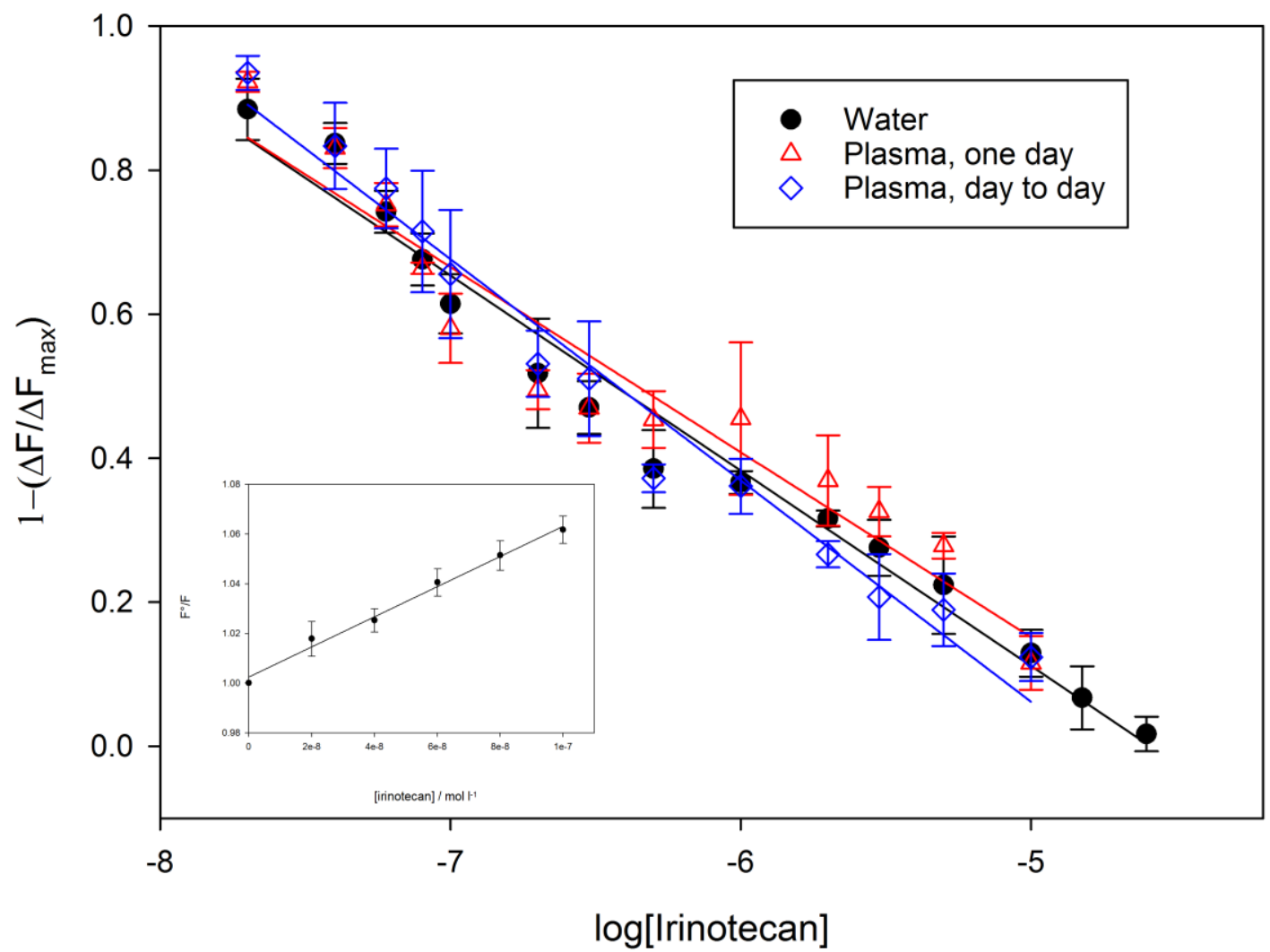


Figure 7: Fluorescence of MIP 1.5 at increasing concentration of irinotecan. Black: in water : acetonitrile mixture; red: in human plasma : acetonitirile; blue: average calibration over repeated measures carried out in three different days along one month. Error bars from the average of triplicates for the black and red series, and from the average of the three replicas (each one triplicate) for the blue series. Insert: Stern-Volmer plot in water : acetonitrile.

In this experiment a very high sensitivity for irinotecan was obtained, with a LOD of $16 \mathrm{nM}$, estimated with the $3 \sigma$ method. We have therefore investigated MIP 1.5 performance in spiked human plasma samples, and the polymer was titrated with increasing amounts of irinotecan in 3:1 acetonitrile : plasma mixture after removal of plasma proteins. Also in this environment, the intensity of MIP 1.5 fluorescence emission decreased upon interaction with the drug showing a linear response within $20 \mathrm{nM}$ and $25 \mu \mathrm{M}$ range. At low drug concentration, within the range $20 \mathrm{nM}$ - $100 \mathrm{nM}$, the apparent Stern Volmer and quenching constants were calculated. The obtained values are $6.07 \cdot 10^{5} \mathrm{Lmol}^{-1}$ and $7.32 \cdot 10^{13} \mathrm{Lmol}^{-1} \mathrm{~s}^{-1}$ respectively, fully comparable with those obtained in water. The overall trend, reported in Figure 7 (red series) is almost superimposable to that obtained in water. The LOD in plasma turned out $12 \mathrm{nM}$, again almost identical to that in water. The intraassay precision on a single triplicated titration was $10.2 \%$ along the whole dynamic range. The response of the MIP sensor is very stable and reproducible during time. The blue series in Figure 7 reports the average outcome of repeated experiments carried out over one month. The sensitivity is not changed after this period, with an average LOD of $10 \mathrm{nM}$, while the inter - assay precision of the whole curve is $13.2 \%$. However, it must be noted that the whole trend as reported in Figure 7, is not fully linear, despite the fact that all the series can be fitted to straight lines with $r^{2}>0.98$. A clear inflection can be in fact observed between $500 \mathrm{nM}$ and $1 \mu \mathrm{M}$ irinotecan, in all the experiments. This is likely due to the presence of two populations of binding sites inside the MIP particles. A minority of binding sites has either higher affinity or higher sensitivity towards quenching from irinotecan and leads to the first linear region, while the less responsive major fraction of binding sites operates at higher concentrations. A similar bimodal behaviour have been observed by us also in our previous work on coumarin - based MIP for sunitinib. ${ }^{16}$ Nevertheless, the dynamic range investigated is within the therapeutic range of irinotecan, which spans between $17 \mathrm{nM}$ and $17 \mu \mathrm{M}$.

\section{Conclusions}

In conclusion, we have prepared a set of MIPs than can rebind irinotecan with good sensitivity. The fluorescence change upon rebinding of the napthalimide - containing MIP allows the detection of irinotecan in spiked human plasma, in a tenth $\mathrm{nM}$ to tenth $\mu \mathrm{M}$ range, after simple treatment of plasma with acetonitrile and removal of the proteins. The proof of concept given with this result is 
very encouraging as to the possibility of developing a portable device with sensors based on fluorescent imprinted nanogels for the detection of irinotecan. We are currently working towards this aim.

\section{Acknowledgment}

We acknowledge the AIRC5_1000 grant 12214 “Application of Advanced Nanotechnology in the Development of Innovative Cancer DiagnosticsTools".

\section{References}

${ }^{1}$ Fukuoka M. (2001) “Current status of irinotecan in lung cancer” Oncol. 15 (suppl 1):6-7

${ }^{2}$ Rodríguez Cáceres M.I., Durán-Merás I., Ornelas Soto N.E., López de Alba P.L., López Martínez L. (2008) "Spectrofluorimetric determination of irinotecan in the presence of oxidant and metal ions" Talanta 74: 1484-1491

${ }^{3}$ Weekes J., Lam A. K. Y., Sebesan S., Ho Y. H. (2009) "Irinotecan therapy and molecular targets in colorectal cancer: A systemic review” World J. Gastroenterol. 15(29): 3597-360

${ }^{4}$ Alnaim L. (2007) Therapeutic Drug Monitoring of cancer chemotherapy, J. Oncol. Pharm. Pract. 13: $207-221$

${ }^{5}$ Ragot S., Marquet P., Lachatre F., Rousseau A., Lacassie E., Gaulier J.M., Dupuy J.L., Lachatre G. (1999) "Sensitive determination of irinotecan (CPT-11) and its active metabolite SN-38 in human serum using liquid chromatography-electrospray mass spectrometry" J. of Chromatogr. B 736: $175-184$

${ }^{6}$ Marangon E., Posocco B., Mazzega E., Toffoli G. (2015) "Development and Validation of a HighPerformance Liquid Chromatography-Tandem Mass Spectrometry Method for the Simultaneous Determination of Irinotecan and Its Main Metabolites in Human Plasma and Its Application in a Clinical Pharmacokinetic Study" DOI:10.1371/journal.pone.0118194

${ }^{7}$ Hahn R.Z., Arnhold P.C., Andriguetti N.B., Schneider A., Klück H.M., dos Reis S.L., Bastiani M.F., Kael I., Cezimbra da Silva A.C., Schwartsmann G., Antunes M.V., Linden R. (2018) "Determination of irinotecan and its metabolite SN-38 in dried bloodspots using high-performance liquid-chromatography with fluorescence detection" J. of Pharm. and Biomed. Anal. 150: 51-58

${ }^{8}$ Calandra E., Crotti S., Nitti D., Roverso M., Toffoli G., Marangon E.,Posocco B., Traldi P., Agostini, M. (2015) "The development of a matrix-assisted laser desorption/ionization (MALDI)based analytical method for determination of irinotecan levels in human plasma: Preliminary results" J. Mass Spectr. 50(7), 959-962

${ }^{9}$ Vlatakis G. Andersson L. I., Müller R., Mosbach K. (1993) "Drug Assay using antibody mimics made by molecular imprinting" Nature 361: 645-647

${ }^{10}$ Roy B., Vo Duy S., Puy J.I., Martin C., Guitton J., Dumontet C., Périgaud C., Lefebvre-Tournier I. (2012) "Synthesis and Evaluation of a Molecularly Imprinted Polymer for Selective Solid-Phase Extraction of Irinotecan from Human Serum Samples" J. Funct. Biomater. 3: 131-142

${ }^{11}$ Xue J.Q., Li D. W., Qu L. L., Long Y. T. (2013) "Surface-imprinted core-shell Au nanoparticles for selective detection of bisphenol A based on surface-enhanced Raman scattering" Anal. Chim. Acta 777: 57-62 
${ }^{12}$ Ciardelli G., Cioni B., Cristallini C. (2004) "Acrylic polymeric nanospheres for the release and recognition of molecules of clinical interest" Biosens. Bioelectron 20: 1883-1090

${ }^{13}$ Pasetto P., Maddock S. C., Resmini M. (2005) "Synthesis and characterization of molecularly imprinted catalytic microgels for carbonate hydrolysis" Anal. Chim. Acta 542: 66-75

${ }^{14}$ Flavin K., Resmini M. (2009) "Imprinted nanomaterials: a new class of synthetic receptors" Anal. Bioanal. Chem. 393: 437-444

${ }^{15}$ Liu H., Hong Y., Chen L. (2015) "Molecularly imprinted polymers coated on carbon nanotubes for matrix solid phase dispersion extraction of camptothecin from Camptotheca acuminate" Anal. Method. DOI: 10.1039/c5ay01721a

16 Pellizzoni E., Tommasini M., Marangon E., Rizzolio F., Saito G., Benedetti F., Toffoli G., Resmini M., Berti F. (2016) "Fluorescent molecularly imprinted nanogels for the detection of anticancer drugs in human plasma" Biosens. Bioelectr.86: 913-919

${ }^{17}$ Puoci F., Gereffa C., Iemma F., Muzzalupo R., Spizzirri U. G., Picci N. "Molecularly imprinted solid phase extraction for detection of sudan I in food matrices" Food Chem. 93(2):349-353

18 Scorrano S., Mergola L., Del Sole R., Vasapollo G. (2011) "Synthesis of molecularly imprintedpolymers for amino acid derivates by using different functional monomers" Int. J. Mol. Sci.12:1735-1743

${ }^{19}$ Caro e., Marcé R. M., Cormack P. A. G., Sherringhton D. C., Borrull F. (2003) "On-line solidphase extraction with molecularly imprinted polymers to selectively extract substituted 4chlorophenolsand 4-nitrophenol from water" J. Chromatogr. A 995:233-238

${ }^{20}$ Roy S. G., De P. (2014) "pH Responsive polymers with aminoacids in the side chains and their potential applications" J. Appl. Polym. Sci. 41084:1-12

${ }^{21}$ Konstantinova T. N., Miladinova P. M. (2008) "Synthesis and properties of some fluorescent1,8naphthalimide derivatives and their copolymers with methyl methacrylate" J. Appli. Polym. Sci. 111(4):1991-1998

${ }^{22}$ Servant A., Rogers S., Zarbakhsh A. and Resmini M. (2013) "Polymeric organic nanogels: structural studies and correlation between morphology and catalytic efficiency" New J. Chem., 37, 4103

${ }^{23}$ Lakowicz J.R. (2006) "Principles of Fluorescence Spectroscopy” Third Edition, Springer, ISBN13: 978-0387-31278-1

${ }^{24}$ Guzow K., Rzeska A., Mrozek J., Karolczak J., Majewski R., Szabelski M., Ossowski T., Wiczk W. (2005) "Photophysical properties of tyrosine and its simple derivatives in organic solvents studied by time-resolved fluorescence spectroscopy and global analysis" Photochem. Photobiol. 81(3):697-704

25 Szabo A.G., Rayner D.M. (1980) "Fluorescence decay of tryptophan conformers in aqueous solution" J. Am. Chem. Soc. 102(2):554-563

${ }^{26}$ May B., Poteau X., Yuan D., Brown R.G. (1999) “A study of a highly efficient resonance energy transfer between 7-N,N-diethylamino-4-methylcoumarin and 9-butyl-4-butylamino-1,8naphthalimide" Dyes Pigm. 42:79-84

27 Sterling H.J., Prell J.S., Cassou C.A., Williams E.R. (2011) "Protein Conformation and Supercharging with DMSO from Aqueous Solution” J. Am. Soc. Mass Spectrom. 22:1178-1186

${ }^{28}$ Tjernberg A., Markova N., Griffiths W. J., Hallen D. (2006) "DMSO-related effects in protein characterization" J. Biomol. Screen. 11(2):131-137 